\title{
LA LITERATURA DE PROTESTA EN EL ECUADOR
}

\author{
POR \\ MIGUEL DONOSO PAREJA \\ Casa de la Cultura Ecuatoriana, Guayaquil
}

- ¿Qué significan esas cruces?

- ¿Cómo, no sabe, jefe? ¿No es de aquí?

-De aquí soy, pero he pasado algunos años fuera.

- Ahí adebajo de donde están las cruces hay fondea. dos cientos de cristianos, de una mortandad que hicieron hace años. Como eran bastantísimos, a muchos los tiraron a la ría por aquí, abriéndoles la barriga con bayoneta para que no rebalsaran. Los que enterraron en el panteón descansan en sagrado. A los de acá icómo no se les va a poner la señal del cristiano, siquiera cuando cumplen años?

Entonces Alfonso reparó en la extraña coincidencia: ese día era 15 de noviembre.

- ¿Quién las pone?

-No se sabe: alguien que se acuerda.

Joaquín Gallegos Lara

E1 texto del epígrafe que preside este artículo (Gallegos Lara, Obras escogidas, pp. 245-246) nos remite a una triple pregunta: ¿protesta, compromiso, testimonio?, y a la necesidad de aclarar los excesos significativos de cada uno de estos términos. Es protestataria, por ejemplo, la actitud de nuestros poetas de la llamada «generación decapitada», a los que Agustín Cueva (Lecturas y rupturas, pp. 49-50) se refiere en la siguiente forma:

El primer movimiento poético de importancia del siglo xx se produce como reacción simultánea contra esa sociedad y contra estas secuelas del romanticismo. En efecto: reaccionaria en lo social, renovadora en lo estético, la generación de 1910, llamada «modernista» o «de- 
capitada», se halla integrada básicamente por miembros de la aristocracia criolla, que hacen de la poesía un vehículo para expresar su disconformidad con el ambiente «municipal y espeso» creado por la Revolución Liberal; vale decir, su desadaptación en una sociedad donde el aristócrata ha dejado de ser amo y señor absoluto. Arturo Borja (18921912), Ernesto Noboa Caamaño (1889-1927) y Humberto Fierro (18901929) se encierran en la torre de marfil del spleen y la literatura refinada; atacan la "vulgaridad» de los tiempos en que les ha tocado vivir; se dan a las drogas hasta morir prematuramente a causa de ellas (de ahí el nombre de «decapitados» que les endilgara el ensayista Raúl Andrade); y en las veladas «palatinas» rinden culto a sus vates preferidos: Laforgue, Rodenbach y, sobre todo, Samain y Verlaine. Producen una obra poética que ha sido inscrita por los críticos nacionales en la corriente modernista, pese a que la influencia más directa que reciben los «decapitados» no es la de Rubén Darío, sino de los simbolistas franceses ${ }^{1}$.

Esta «protesta» de nuestros «decapitados», sin embargo, no correspondería, en manera alguna, a lo que se conoce y admite de manera general como literatura comprometida (¿de o con compromiso?), la misma que, en términos generales, estaría signada por la idea de lo nuevo en lo que se refiere a lo social, aunque no siempre en lo estético.

Dentro de esta idea de «lo nuevo», de lo revolucionario, se inscribe la noción de «literatura comprometida», y lo hace con características muy precisas, subrayadas por Lunacharsky (El arte y la revolución, pp. 291294) en estas palabras:

... el escritor, unas veces consciente y otras inconscientemente, se presenta también como un predicador. Puede expresarse líricamente, es decir, expresando directamente sus ideas y emociones, o puede hacerlo en forma épica o dramática; es decir, ofreciendo unos hechos como reflejo objetivo de una realidad, como si estos hablaran por sí mismos, pero escogiéndolos de tal modo que involuntariamente inclinaran al lector hacia unas determinadas conclusiones. El arte es, por tanto, una fuerza social. El arte es un poderoso instrumento de propaganda.

«Este escritor - continúa Lunacharsky - puede aspirar a organizar la voluntad y los sentimientos de su clase, dándoles una brillante expresión», para, poco después, concluir: "Hay que partir de las mejores formas ya conseguidas, vertiendo en ellas nuestro nuevo contenido».

1 Tampoco puede considerarse que la obra de los «decapitados» fuese «renovadora en lo estético» si consideramos que tanto el modernismo como el simbolismo databan de siquiera cincuenta años atrás en el contexto literario general. 
Finalmente, el teórico soviético expresa que, para conseguir sus objetivos, el escritor comprometido «puede hacerlo, en general, en dos distintos planos: como arte de agitación $\mathrm{y}$, digamos, como gran arte. E1 arte de agitación ve, ante todo, el objetivo social. Quiere sinceramente enseñar, pero en una forma más o menos sagaz y emotiva. Reviste sus enseñanzas con el arte y las convierte, de este modo, en más efectivas.

Sería absurdo en extremo que nos disgustara o repugnara el arte de agitación. En nuestro país, fundamentalmente campesino y semianalfabeto, éste desempeña un enorme papel. Se puede pensar en unos maestros de carácter especial, los agitadores artísticos, que sepan hacer muy bien su trabajo. Pero el maestro del «gran» arte no sólo puede, sino que debe dedicarse al arte de agitación (... $)^{2}$.

Esta propuesta sobre lo que debe ser la literatura comprometida podría resumirse en los siguientes términos:

1. Quien escribe debe ser un predicador, es decir, quien hace una prédica. Prédica $=$ sermón.

2. El texto es un instrumento, esto es, algo que se utiliza para obtener un resultado.

3. La escritura debe ser un hecho propagandístico.

4. E1 objetivo de la literatura debe ser la agitación.

5. El escritor debe enseñar. Consecuentemente, sus textos deben cumplir una función didáctica.

6. Frente a esta función didáctica, la literatura es un simple revestimiento para dotarla de mayor efectividad, y

7. El 'gran escritor' debe dedicarse al arte de agitación.

Desde luego, y lo argumentaré más adelante, no es éste el sentido del compromiso del escritor que utilizaré en este artículo, como tampoco lo será el de literatura de protesta en los términos de los integrantes de la promoción poética de los «decapitados».

En lo que respecta a lo testimonial, a la literatura como testimonio, toda la literatura lo es, en mayor o en menor grado, puesto que siempre proviene de lo real, incluidos nuestros sueños más delirantes, y está referida, incluso contra la voluntad del autor, a un tiempo y un espacio dados.

Asumiremos, entonces, la expresión literatura de protesta en función de lo nuevo, tanto social como formalmente, esto es, como un compromiso con la literatura en sí misma, en su autonomía y su especificidad, y al servicio de sus propios fines, lo que no excluye que tenga contenidos po-

${ }^{2}$ Más características de esta tendencia estética pueden encontrarse en Los grandes de la década del 30, de Miguel Donoso Pareja (Quito: Editorial El Conejo, 1984), pp. 11-12. Los subrayados son míos. 
líticos. Un poco en esta línea, cabe citar a Fernando Balseca (Revista Diners, núm. 56, p. 66), quien nos recuerda que

todo poeta, y por tanto todo artista, busca entregar (...) un mensaje para sus contemporáneos, pero también lo que alienta la creación poética es el deseo de que ese mensaje se haga perdurable en el tiempo. Todo poeta es dueño de una visión personal, no sólo del mundo y su futuro, sino del futuro del poema, porque un poema que alcance a conmover a más de un lector está obligando a los poemas del futuro a comportarse de un modo superior.

Estas palabras de Balseca nos están subrayando la idea de la literatura como un proceso, así como de su perfectibilidad y su acción a largo plazo, su imposibilidad de ser una acción inmediata.

Los mejores productos de nuestra literatura de protesta (o comprometida) se han dado en esta tesitura. Uno de ellos es, sin duda, Las cruces sobre el agua, novela que maneja y combina cuatro focos de significación básicos: la ciudad (Guayaquil), las acciones de los protagonistas, la búsqueda de una identidad y la valoración política de los acontecimientos. Su culminación y detonante argumental es la masacre del 15 de noviembre de 1922.

Sin embargo, el centro significativo totalizador de esta novela es la expresión de una toma de conciencia de clase de los personajes a través de diferentes hechos históricos y sociales, lo que pudiera hacer pensar que se trata de un texto comprometido según los términos de Lunacharsky.

Y no convierte, porque felizmente la propia organización del discurso novelístico le da autonomía y especificidad, en materia literaria al referente real, que desde entonces no es necesario para su lectura y, de todos modos, está ahí.

Así, los diversos niveles significativos se entrecruzan y se complementan para evitar la linealidad y la obviedad del documento sociológico o político. Los motivos temáticos asociados, en cuanto unidades narrativas, son reforzados constantemente con motivos temáticos libres dinámicos. La trama se ensancha de esta manera, argumenta, pero sin caer en lo declamatorio.

El marco de la ciudad no es tratado en términos sociológicos, sino como un encuadre humano en movimiento, con todas sus pequeñeces y grandezas, una amplia gama de matizaciones. $Y$ es el barrio del Astillero -tradicionalmente popular y combativo, en parte lumpen y en parte obrero- el pulso mismo, la representación de la urbe. De ahí es Alfredo Baldeón, uno de los personajes principales, y su barrio el lugar adonde se trasladaron los astilleros después de su auge en los tiempos coloniales. 
Se trata, pues, de una zona «brava» de la ciudad, de un sector combativo y con tradición. La vida familiar, las peleas callejeras, los juegos de los niños, las relaciones con las muchachas, los trabajos (o su ausencia), ia lucha por subsistir, etc., van configurando la imagen de la ciudad a partir de uno de sus sectores más representativos.

Alfredo Baldeón vive y crece en la ciudad, es testigo en su niñez de la epidemia de peste bubónica, se mueve dentro de su violencia primitiva, su sexualidad, sus prejuicios radicales, su división en clases, los reclutamientos para «la guerra de Esmeraldas» - prolongación de las montoneras liberales, bajo el liderazgo de Carlos Concha-, los viajes de la gente (el guayaquileño tiene, casi siempre, una época en que se va de marinero) y, finalmente, participa en la huelga general de noviembre de 1922 .

Así, las acciones de los protagonistas, sus vidas, están constantemente reforzadas, en su significación, por el contexto en que se mueven. Pero lo más importante es que son individuos, seres humanos que actúan y sienten, no títeres de ese contexto. Su toma de conciencia no es idílica ni automática, menos aún metafísica, sino que se da dentro de las contradicciones de una psicología social manipulada (la que hace, por ejemplo, que Baldeón responda muchas veces con una violencia indiscriminada) y la presencia real de la represión sangrienta contra los trabajadores.

Por todo lo anterior, en el texto se mezclan defectos y virtudes: religiosidad, machismo (en todas sus variantes), atisbos de conciencia de clase, creencias mágicas, prejuicios raciales, afírmaciones de nacionalidad, en fin, de todo, en una gama de la cual se podría extraer, aisiándolos de sus partes manipuladas por la ideología dominante, muchos elementos de una auténtica cultura popular.

En definitiva, Las cruces sobre el agua desvirtúa la vieja afirmación de que los narradores del realismo social ecuatoriano, en su totalidad, trazaron sus textos en blanco y negro, sin matices ni hondura.

En cuanto a su textura, tiene a ratos una piel pegajosa y romanticona, costumbrista e idílica en otros, lo que contrasta y rompe a veces la estructura expresiva, que en su generalidad es áspera y directa.

Pese a este defecto, considero que se trata de una novela de gran calidad, de un hito en el desarrollo de la narrativa ecuatoriana, así como uno de los textos mejor logrados de nuestra literatura de protesta. Según e1 chileno Mariano Latorre (uno de los maestros del «criollismo»), debe considerársela entre «las grandes novelas de América Latina».

Con características semejantes en cuanto a factura y en tanto novelas comprometidas, hay otras dos, debidas a narradores de la década de los años treinta, que resulta inevitable mencionar (habría muchas más, pero por lo corto del espacio, y considerando su calidad, éstas son las más signi- 
ficativas). Se trata de El muelle, de Alfredo Pareja Diezcanseco, publicada en 1932, y de Nuestro pan, de Enrique Gil Gilbert, que data de 1942, ambas anteriores, por tanto, a Las cruces sobre el agua, aparecida en 1946.

Según Benjamín Carrión, El muelle es una novela de izquierda, que es lo mismo que decir de protesta o comprometida, pero sin que el autor se ponga etiqueta ni rótulo. En efecto, desde un punto de vista de «izquierda», Pareja construye en este texto una ajustada y eficaz metáfora de la explotación, y digo metáfora porque la linealidad y esquematismo, tan evidentes en Jorge Icaza, por ejemplo (lo que veremos líneas después), adquieren en el escritor guayaquileño una dimensión figurada.

El narrador no se ha puesto etiqueta ni rótulo, es decir, no reclama su «tendencia», sino que ésta aflora, sin ninguna conducción visible, del texto.

Así, esta novela se da en el centro mismo de la crisis exportadora del cacao a raíz de la plaga de la «escoba de la bruja» y con una estructura del lenguaje que es, por lo general, sobria y escueta, de una enorme economía expresiva. Dentro de estas características, El muelle trae manejos temporales y espaciales de planos, así como cierta variedad de tonos, sabiamente integrados para que no produzcan rupturas en el texto como totalidad. En esta tesitura, la historia sucede en Nueva York y en Guayaquil, con flash backs a veces, cierta simultaneidad en otras y, sobre todo, con una acertada atmósfera para cada uno de los dos lugares donde transcurre la acción.

Los personajes protagonistas — Juan Hidrovo y María del Socorro Ibáñez, su mujer- responden a una sintaxis narrativa rica y coherente. Más ella, a la que se ha tratado con profundidad y en sus contradicciones, que no son, en el texto, producto de los determinantes externos únicamente, sino también de su propia interioridad y de una psicología social aguda y lúcidamente captada.

Frente a éstos, otros personajes adquieren relieve. En Nueva York, hasta su muerte, el venezolano Claudio Barrera, con su carácter de adyuvante, igual que «el tío», casi mítico, más un buen número de personajes testigos e informantes que son ubicados con precisión para robusiecer el intercambio de sentidos dentro de lo que se cuenta y llegar, de esta manera, a decir.

Así, lo político entra a formar parte de las necesidades inherentes de la novela, poniéndose a su servicio y no al revés, como sucede en los textos comprometidos de mala o esquemática factura. Esta virtud narrativa es la que borra toda etiqueta y todo rótulo. No hay esquema, por tanto, sino que los personajes son y están, son y accionan, no se encuentran coloca- 
dos en una infraestructura que hace las veces de retablillo en que se mueven, están y accionan como muñecos, esto es, no son, sino que responden, notoriamente, a la gesticulación del autor, que supone, y mal, que no está siendo visto.

Como personaje oponente - ya en Guayaquil - opera don Angel Mariño. Actancialmente es «el malo», pero el narrador no lo califica, no toma partido contra él, sino que sutilmente lo desacredita, lo evidencia para que sea el lector el que llegue, en su más estricto y libre papel de narratario, a las conclusiones éticas a las que todo texto que no solamente cuenta, sino que dice, quiere arribar. En esta intención, Pareja Diezcanseco se apoya en el tono narrativo. $Y$ es irónico, delicada y eficazmente irónico para lograrlo.

Con todas estas virtudes, Pareja se sitúa en lo mejor del realismo social o en, lo que es lo mismo, lo mejor de la novela de protesta o comprometida.

En lo que respecta a Nuestro pan, varias son las tergiversaciones que la han marcado. La más frecuente es la de que se trata de «la novela del arroz». Así, Gil Gilbert habría hecho este relato como Jorge Amado hizo el del cacao, José Eustasio Rivera el del caucho, Fallas el del banano, Alfredo Varela el de la yerba mate, etc.

Esta, por supuesto, es una visión unilateral, porque no es el asunto lo que, en última y definitiva instancia, determina la significación de un texto, sino la manera de mostrárselo y la visión del mundo que en él se revela, y esto a partir del manejo global de los elementos que lo integran.

¿De qué manera utiliza Enrique Gil Gilbert los elementos que conforman su texto en relación al arroz? No, desde luego, como la epopeya de su producción, ni sólo como el símbolo de que es «nuestro pan», el de todos, sin consideración de las divisiones de clase, sino como un elemento circunstancial. Dentro de esta propuesta, Gil Gilbert construye y mueve a sus personajes sin declamaciones ni esquematismos, la narración no es lineal: comienza ya, desde aquellos años, a utilizar indicios, a darle verticalidad, grosor a su escritura, y las relaciones de producción que provoca el monocultivo son el factor constructivo de mayor incidencia en el conjunto, considerando, eso sí, los matices de la ideología dominante, la psicología social de los trabajadores, su mayor o menor grado de conciencia y los avances de la tecnología. Esto, que pudiera parecer esquemático, tiene su propia dinámica, su organización como discurso. Y todo emerge de esta organización, de la manera como se le presenta el asunto al lector. Al mismo tiempo, la lectura necesita de una concepción del mundo diferente, capaz de evadirse de los parámetros alienados de los propios personajes (excepto los de aquellos cuya conciencia de clase ha desarrollado) 
y llegar a las connotaciones del discurso, librarse de sus supuestas y aisladas expresiones denotativas.

Más complejo en su organización discursiva, renovador desde 1927 de nuestro realismo, Pablo Palacio es también un escritor de protesta. Bastará para demostrarlo transcribir unos cuantos párrafos de Vida del ahorcado (Palacio, pp. 117-118), párrafos que parecerán obvios y denotativos al sacárselos de su contexto y del tono general de la novela. Con esta advertencia hago la extensa cita, que evidencia sin duda el carácter comprometido de la escritura del gran narrador lojano. Dice:

Quería explicaros que soy un proletario pequeñoburgués que ha encontrado manera de vivir con los burgueses, con los buenos y estimables burgueses.

He aquí un producto de las oscuras contradicciones capitalistas que está en la mitad de los mundos antiguo y nuevo, en esa suspensión del aliento, en ese vacío que hay entre lo estable y el desbarajuste de lo mismo. Tú también estás ahí, pero tienes un gran miedo de confesarlo porque uno de estos días deberás dar el salto y no sabes si vas a caer de este o del otro lado del remolino. Mas aquí mismo estás enseñando las orejas, amigo mío, tú, enemigo del burgués que ignoras el lado en donde caerás después del salto.

Pero ya me lo aclaras todo: Estoy viviendo la transición del mundo. Aquí, delante de mí, está la volcadura de la campana, del otro lado de la justicia, y aquí mismo, dentro de mí, están todos los siglos congelados, envejecidos y grávidos. Yo tengo un amor en esos siglos; yo tengo un amor en esa volcadura.

Mi padre y mi madre están allá sin comprenderme. Mi padre y mi madre son mis enemigos primeros. No les llegó la voz a tiempo y el tiempo de llegar la voz ha puesto un siglo entre uno y otro. $Y$ he aquí que estamos para con ellos tan próximos como lejanos en el mismo momento.

¿Eh? Anda levántate, enciende algo, que estás retardando el equilibrio definitivo del mundo. Después verás lo que haces ante los ojos húmedos de la madre. Pero eso al fin qué importa. Toda traba es burguesa.

Lo que sucede es que tienes pena de tu vaca y de tu cochino. Estás enamorado de tu vaca y de tu cochino y en lo sucesivo no se te van a permitir esas pasiones bestiales.

Mira, vamos a hacer una nueva vida. Una nueva vida maravillosa. Vamos a suprimir la corbata y el cuello. Vamos a permitir que todos los hombres se dirijan la palabra con el sombrero puesto. Vamos a prohibir las genuflexiones y las reverencias. Todos podremos vernos cara a cara. ¿Qué más quieres? ¿Qué es lo que vas a perder con eso? 
A pesar de su aparente obviedad, estos párrafos están cargados de ironía y de sentidos que no cabe desentrañar aquí. Al mismo tiempo, es importante señalar que el punto de vista cambia: Palacio habla (escribe) desde adentro, desde el ojo del huracán, con un cúmulo de tensiones internas, de contradicciones y de confrontaciones. Su realismo es mucho más profundo y conflictivo.

Naturalmente, el número de novelas y volúmenes de cuentos comprometidos o de protesta es muy amplio, con algunos textos de excelente factura, como Exodo de Yangana, de Angel F. Rojas, por ejemplo, o Los que se van (Aguilera Malta, Gil Gilbert y Joaquín Gallegos Lara), pero no se trata de hacer un catálogo, sino de señalar características.

Dentro de esa amplia gama de textos de protesta es dable mencionar, sin embargo, prácticamente todos los títulos de Jorge Icaza, presididos por Huasipungo y El chulla Romero y Flores; Los Sangurimas, de José de la Cuadra; algunas de las novelas y piezas dramáticas de Demetrio Aguilera Malta; los textos del primer período de Humberto Salvador; casi todos los de Pareja Diezcanseco; los de Pedro Jorge Vera, a quien el cubano Salvador Bueno califica en su prólogo a Los animales puros (p. 25) de «escritor político»; y los de Nelson Estupiñán Bass, entre otros; y eso refiriéndome sólo a los escritores de la promoción de la década de los años treinta, puesto que desde sus inicios nuestra narrativa se ha particularizado por su carácter contestatario, como veremos más adelante.

Si consideramos los planteamientos del realismo socialista (Lunacharsky), dentro de nuestra literatura comprometida los más cercanos son Jorge Icaza y Humberto Salvador en su primer período, más éste que aquél.

Iniciador de nuestro indigenismo (Huasipungo, 1934), puesto que lo anterior escrito en el país sobre los indios es más bien «indianismo», Icaza amplía su constelación temática enrumbándose hacia lo mestizo, a lo que él llama «el cholerío». Su esquema es «perfecto», y, más que en ningún otro texto, En las calles.

En esta novela, la arquitectura temática (¿estructura de contenidos?, como diría Lotman), la columna vertebral dentro de la que operan sus personajes está impecablemente organizada y va del campo a la ciudad con una perfección tal que resulta literariamente inverosímil.

Dentro de este ensamblamiento de tanta precisión, sin un solo cabo suelto, la delgadez de la escritura, sitiada en un estar y un accionar que elimina la posibilidad de ser, la inserción del sujeto en lo real resulta por demás incompleta porque «el sujeto» (cito a Aníbal Farías, «El lugar de la poesía», ponencia en el III Encuentro sobre Literatura Ecuatoriana, Cuenca, noviembre de 1984) «se encuentra escindido en y por el signifi- 
cante, por el lenguaje que constituye un orden por el que tiene necesariamente que pasar. De esta sujetación, consecuentemente, nace el hecho mismo del sujeto, de que haya sujeto».

Al fallar el lenguaje - por lo denotativo y una ausencia de excesos de significación-, En las calles queda reducida al esquema, sin un sujeto (o sujetos) que la revitalicen.

En 1936 Humberto Salvador publica Trabajadores, novela en la que aparecen muchos de los elementos postulados por el realismo socialista.

Los ejemplos, en este sentido, son muchísimos, y voy a consignar sólo algunos:

1. Venid alrededor de la carne dolorida de papá, proletarios del universo. Uníos y seréis fuertes. Formaréis un solo cerebro, un inmenso corazón, un único brazo, y conquistaréis el poder. La tierra, la riqueza y el trabajo serán de vosotros y para vosotros (p. 147).

2. La sangre revolucionaria de mi padre se cristalizará a través de las generaciones. De ella, de las entrañas de todos los mártires, brotará luminosa la nueva humanidad (p. 147).

3. - La razón es muy clara - añade mi padre-. Esos incapaces no hacen sino obedecer los mandatos de la clase dominante. En realidad, no son sino fantoches que defienden intereses ajenos. $Y$, naturalmente, la clase capitalista casi nunca puede contar con los hombres superiores, porque éstos pertenecen a las filas revolucionarias (p. 156).

4. - iNo hay esperanza ninguna para el pobre! -exclamó Lola. -Al contrario - dice mi padre-. Existe para el proletariado una gran esperanza. La de unirse, formar una sola fuerza y organizarse para conquistar el poder (p. 160).

5. iSu hermano es el primer soldado de la revolución en el Ectrador! iSu hermano es un precursor y un mártir! (p. 170).

6. Los trabajadores de todos los países crearemos la nueva humanidad (p. 191).

Con esta última frase principia y culmina el libro, en absoluta coherencia con las propuestas del realismo socialista: servir a la política, educar, publicitar y agitar. En efecto, los ejemplos transcritos corresponden nítidamente a la condición de consignas, con el agravante de que son consignas proletarias que se aplican, mecánicamente, a artesanos, empleados y subempleados, soldados y policías.

Lo argumentado hasta aquí se refiere, exclusivamente, a los narradores de la década de los treinta. Habría que examinar ahora, aunque sólo sea someramente, lo que sucedía en los años anteriores a nuestro llamado realismo social. 
De unos pocos años acá, hay consenso generalizado de que nuestra primera novela es La emancipada, de Miguel Riofrío, aparecida como folletín del diario La Unión (Quito) en 1863 y reeditada (rescatada) por el Consejo Provincial de Loja al lanzarla como libro en 1974, con prólogo de Alejandro Carrión. La Universidad de Cuenca, a través de su departamento de Difusión Cultural, hizo una nueva edición, esta vez con un estudio introductorio de Antonio Sacoto, y Editorial El Conejo la incluye entre los doce títulos que conforman su colección Joyas Literarias.

Con su aparición nos encontramos frente a una novela de protesta.

Se trata de un texto breve que se ubica dentro del pensamiento liberal de la época, siendo su motivo central el enfrentamiento de dos concepciones educativas: la de la madre de la protagonista, que es liberal, y la del padre, que es conservadora.

En este contexto, el narrador opta por la postura liberal y conduce su historia a criticar - y a responsabilizar por las consecuencias que desencadena la confrontación - al padre y al medio retardatario frente a las ideas avanzadas de la madre y de la protagonista. En última instancia hay, pues, «dos emancipadas», y el mérito fundamental de la novela es su postura (su compromiso), anticipada para la época y propugnadora de la liberación de la mujer respecto a sus roles tradicionales. Literariamente, en cambio, deja mucho que desear, en especial por la frecuente participación del autor opinando sobre los hechos y los personajes, lo que instaura un discurso moralizante.

En realidad, La emancipada es un verdadero alegato en defensa de la mujer y un aporte auténtico, pese a su pobreza expresiva, para constatar, desde entonces, una vertiente ideológica progresista en nuestra narrativa.

Dentro de esta línea ideológica, pero muchísimo mejor construida y expresada, es Timoleón Coloma, de Carlos R. Tovar, cuya aparición data de 1888 y es una especie de anticipación de Las tribulaciones del joven Torless, de Musil. En mi opinión, esta noveleta de Tovar es precursora de una corriente temática que abriría su constelación expresiva en Latinoamérica a partir de los años en que recrudeció (y se promocionó) el llamado «conflicto generacional», con obras y autores como La ciudad y los perros, de Vargas Llosa; Los geniecillos dominicales, de Julio Ramón Ribeiro; De perfil, de José Agustín; Desnudo en el tejado y Tiro libre, de Antonio Skármeta; Para comerte mejor, de Eduardo Gudiño Kieffer, etc.

A grandes rasgos, podemos señalar varias líneas o bloques temáticos en Timoleón Coloma. En primer lugar, la autoridad, representada por la escuela y la familia. Como contrapartida, la sensación de impotencia del subordinado a esos poderes, que a la postre son uno solo y, en definitiva, una metáfora del poder en general. Luego vendría el enfrentamiento del 
niño con los demás, es decir, los otros, lo que se convierte en un anticipo de lo que son el mundo y sus habitantes, no lo que uno creía que eran a partir de una visión falseada o ideal, introyectada por los mayores.

Estos bloques temáticos, congruentes entre sí, incluyen sus opuestos, y es allí donde se deposita la tensión narrativa, con un enfrentamiento global que podría traducirse en sometimiento-liberación (o supuesta liberación).

Siendo la niñez y la adolescencia equivalentes a sometimiento al poder, tanto de la familia como de la escuela, crecer -- dejar de ser niños y adolescentes- implicaría liberación. Aparece entonces, dentro de la tensión del relato, otro bloque temático: el crecimiento y, junto a él, el amor como apetencia del sexo opuesto, de la mujer en este caso.

Finalmente, la novela se cierra - y abre a la vez-con la definición de la realidad última, aquella que estará marcada por el lapso en que se desarrolla la historia: desde la niñez escolar hasta los veintiún años, esto es, la mayoría de edad, fecha clave que, desde el poder, marca una liberación que nos lleva a nuevos sometimientos.

En estos términos, todo el texto es una especie de gran anticipación ciega que, aun marcando en qué terminan cuando adultos algunos de los personajes, deja abierta al lector la idea de que llegará a ser el protagonista quien, una vez más, se enfrentará a la realidad desde lo que él cree que será el mundo ahora (a los veintiún años) y lo que, en definitiva, podrá ser.

Desde La emancipada, por lo demás, el relato ecuatoriano se dirige voluntariosamente hacia el realismo, dentro de una secuencia que viene desde el realismo costumbrista y criollista de Riofrío - pasando por algunos momentos naturalistas, ciertas gotas de modernismo tardío y un indianismo de origen romántico - hasta el realismo social que estalla en Los que se van, o el «realismo abierto» de Pablo Palacio.

En la línea de la protesta y el compromiso -mirados éstos siempre como el enfrentamiento de lo viejo con lo nuevo- varios textos son mencionables, como Relación de un veterano de la independencia, de Carlos R. Tovar, que data de 1895; Capítulos que se le olvidaron a Cervantes, de la misma fecha, novela en la que Montalvo incluye como personajes, para burlarse de ellos, a algunos de sus enemigos políticos ${ }^{3}$; Pacho Villa-

${ }^{3}$ Sobre esto señala Jorge Enrique Adoum, en La gran literatura ectiatoriana del 30 (Quito: Ed. El Conejo, 1984), p. 26, lo siguiente: «Los Capítulos que se le olvidaron a Cerizantes son importantes para seguir la evolución del pensamiento social latinoamericano, y, sobre todo, porque al mismo tiempo que stupone la continuación del género novelístico iniciado por Mera, constituye entre nosotros el primer 
mar (1900), de Roberto Andrade, y A la costa, de Luis A. Martínez, el antecedente más próximo del realismo social, publicada en 1904. El progresismo de todos estos textos descansa ideológicamente en los postulados del liberalismo y en el enfrentamiento político correspondiente en esos años.

Cabe aclarar aquí que al desarrollar el tema de la literatura de protesta en el Ecuador he considerado únicamente la prosa de ficción y la poesía, y no el ensayo (de cuyo compromiso tendría que hablarse en forma harto diferente) ni el teatro (por los elementos no precisamente literarios que lo conforman en su totalidad).

Respecto a Pacho Villamar, novela nítidamente de protesta, Roberto Andrade realiza - como acertadamente señala Angel F. Rojas (La novela ecuatoriana, pp. 109-110) - «el retrato de una época: en la que imperaba García Moreno». En los términos del compromiso y la protesta, resulta utilísimo completar la cita que hemos hecho líneas antes, misma que prosigue de esta manera:

De seguro se recarga el tinte lóbrego de los cuadros, pues Andrade, dado su temperamento, nunca pudo ser objetivo, y estaba demasiado hundido en la lucha para ser imparcial; pero en las páginas del libro aparecen los atributos que hacían ignominiosa la dictadura del gran autócrata guayaquileño: el vasallaje espiritual al cual tenía sometidas a las ciudades y los campos, el fanatismo de la clase inferior quiteña arteramente explotada por los conventos; la alianza de éstos con el gobierno, para perpetuar la hegemonía clerical sobre las consciencias, a cambio de regalías para la iglesia, que predicaba la sumisión de la gente al católico mandatario; y, por otro lado, el ambiente universitario en el cual alentaba el calor de la rebeldía contra el amo supremo; la presencia de la juventud que leía a Montalvo a escondidas y vibraba de pasión por la libertad. Allí podemos ver gestarse la tempestad que descargó su rayo en medio de la carrera política de García Moreno. El propio Montalvo aparece en Pacho Villamar, como personaje importante del libro y padre espiritual del héroe.

En lo que respecta a $A$ la costa, se trata, en opinión de Jorge Enrique Adoum (La gran literatura ecuatoriana del 30, pp. 27-28), de «la primera. novela ecuatoriana" y la "primera expresión de la voluntad de ver y expresar el país», a lo que agrega:

ejercicio del derecho a imaginar, a hacer de la ficción una réplica de la realidad - allí están, junto a Don Quijote, algunos políticos de Montalvo-, pero sin quedar: prisionera en ella.» 
Lo explica mal: no desmonta el mecanismo económico del sistema, sino que atribuye su funcionamiento a las ideologías en pugna. Martínez crea personajes y situaciones para demostrar, más que para mostrar, lo nocivo de la ideología conservadora: el fanatismo católico, el poder de la Iglesia, la educación confesional, conspiran contra el amor de la heroína y la convierten en amante del sacerdote que la seduce. Pero también hacen de su hermano -el protagonista central- un ser indeciso, tímido, casi cobarde. Burócrata desempleado, conservador convertido al liberalismo durante la guerra civil de 1895 en que triunfa la revolución liberal, pequeño burgués obligado a trabajar la tierra en la Costa, serrano víctima del regionalismo, está a punto de ser feliz: tiene una mujer que ama: ve ante él la posibilidad de hacer fortuna, espera un hijo. Pero el héroe de tantas peripecias será víctima no del sistema ni de la ideología, no de los hombres y sus pugnas, sino del paludismo, del trópico: lo mata la geografía, que Martínez ve bien: en su obra está descrito, quizá con exceso, el paisaje de la Sierra andina y de la Costa tropical, únicas regiones ecuatorianas donde puede transcurrir (aquí cabe preguntar si no sería mejor decir podía) el relato ecuatoriano porque es en ella donde se dan los contextos sociales, históricos y económicos dentro de los cuales es concebible la acción de los personajes.

Novela con marcados énfasis naturalistas, incluso románticos, A la costa es, sin embargo, el texto más voluntariosamente novelesco escrito hasta la fecha en el marco de la literatura de protesta.

Ya en referencia a los inicios del liberalismo en el poder, se publica, tardíamente (en 1940), El cojo Navarrete, de Enrique Terán, novela comprometida en que hay atisbos de un pensamiento socialista en sus personajes. Escrita por un socialista, es la novela de la decepción del liberalismo. El personaje protagonista es un combatiente de extracción popular, baldado de guerra, quien termina en la delincuencia. Es decir, el sacrificio ha sido inútil. Leamos el siguiente diálogo de la novela que lo enfatiza:

Después de volver a llenar las copas, Panchi preguntó al chalán:

-Somos de confianza. Desde que saliste de onde el General Galarza, ¿con qué te has sostenido? sona.

-Con cincuenta sucres que me regaló mi General Alfaro, en per-

- ¿El mismo General Alfaro le dio con sus manos?

-Sí, joven Torcuato; con sus manos me dio y me dijo que la patria recordaría mi nombre con gratitud, porque soy un héroe...

-Qué más, pes -comentó sarcásticamente el Yangüez.

- iCincuenta sucres! - susurró el Panchi, con su voz de bajo profundo-, icincuenta sucres por una pierna!... ¡Qué ganancia! 
Más adelante, y en forma absolutamente obvia, didáctica, interviene el narrador para despejar cualquier duda de lectura, y subraya:

... formaban el grupo de seres sociales que esperan el impulso exterior para volcarse en los caminos morbosos de la ilegalidad, sin poder hallar la sublimación revolucionaria clasista.

Por eso, sin duda, en cada criollo hay un caudillo y un esclavo. Para ser caudillo se requiere el poncho demagógico de las canciones doctrinarias; para ser esclavos, creer en Dios y en el derecho de la propiedad privada...

Navarrete ya no creía ni en lo uno ni en lo otro; creía en su derecho a la vida, conquistado por el delito, ya que no por la esclavitud...

Este mismo tema se desarrollaría, ya en la década de los años ochenta, en Polvo y ceniza, la excelente novela de Eliécer Cárdenas sobre el bandolero mítico lojano Naún Briones.

Tras este racconto nos encontramos nuevamente en el punto donde comenzó este artículo, es decir, en el lapso en que se desarrolla, afianzándose hasta su transformación, nuestro realismo social, años que vienen desde el inicio de la década de los años treinta hasta mediados de la de los cincuenta, y que ideológicamente se caracteriza por una orientación socialista.

Ya en la renovación de nuestro relato tras el realismo social (que se había renovado en sí mismo, sin duda), la tradición protestataria de nuestra narrativa se mantiene.

Novela experimental y que oscurece propositivamente su discurso, $E l$ lagarto en la mano, publicada en 1965, no elude una actitud comprometida. Es ya, eso sí, un texto que no pretende una eficacia inmediata y didáctica; antes bien, repudia cualquier paternalismo y sus aspiraciones significativas se las plantea a largo plazo.

En el centro de su propuesta, Juan Andrade Heymann subraya la idea de la marginalidad, del grupo réprobo, contrapuesto siempre al otro, a lo otro. Por eso, un grupo está inerte, huyendo, evadiéndose frente a la inminencia del naufragio, mientras otro domina. En este contexto, que inicia una etapa de nuestra narrativa en la que lo central es una crítica (¿autocrítica?) a la incapacidad y divisiones de la izquierda en el país, El lagarto en la mano señala que antes que nada tenemos que avergonzarnos, traicionar todo aquello que nos han dado por cierto, cualquier esquema que nos inmovilice - aunque se disfracen de socialismo-, como en Reivindicación del conde Don Julián, de Juan Goytisolo, que invita a desatar la pulverización de los estereotipos que nos han introyectado para mantenernos inertes en una marginalidad que nos condena. 
En esta misma argumentación, Jorge Enrique Adoum cita a Marx en su novela Entre Marx y una mujer desnuda, publicada en 1976, indicándonos que «la verguienza es ya el principio de la revolución, porque un país que se avergüenza es un tigre que se agazapa y salta». Simultáneamente recalca la pequeñísima dimensión heroica de nuestra confrontación de clase (o su inexistente dimensión heroica), pero también lo que han hecho del país las clases dominantes.

Libro extraordinariamente rico y lúcido, Entre Marx y una mujer desnuda es una visión desolada y sin concesiones de la historia social ecuatoriana de los últimos años, en la que se cumplen, a cabalidad, los elementos de descrédito de la realidad, que es explícitamente la propuesta de Palacio, mencionados por Engels como contribución al cambio de un orden injusto.

No sólo como novelas comprometidas, sino como novelas, sin ningún otro calificativo, hay dos que cabe destacar: Tambores para una canción perdida, de Jorge Velasco Mackenzie, publicada en 1986, y Polvo y ceniza, de Eliécer Cárdenas, que data de 1979.

La novela de Velasco, según señala inteligentemente Fernando Balseca («T'ambores de novela fuerte para la mala lectura de canciones perdidas», en Crónica del río, núm. 1, pp. 46, 48 y 49), «supone una perspectiva inusual dentro de la tradición literaria ecuatoriana», porque «el cimarrón del que nos habla la novela jamás existió en el Ecuador», lo que «quiere decir que la novela en cuestión se nutre de una tradición artística, pero esencialmente el novelista ha tenido que inventarse una tradición para hacer existir la novela como tal», lo que no significa, en momento alguno, que carezca de compromiso por su esencialidad fabuladora porque «uno es el lugar del que fuga, otro el lugar del que persigue, si hay fuga es porque no se está con el que manda». Así, la dimensión de la fuga no aparece como un acto cobarde, sino más bien como un eje de oposición, aun ideológica, al poder constituido. Finalmente, Balseca considera, y tiene razón, que

la tradición sobre la que se asienta el texto (la tradición africana, la búsqueda de la esencia de la ciudad de Guayaquil) no se podrá repetir en ninguna otra novela. Los futuros novelistas que aborden el tema Guayaquil tendrán que hacer lo posible por evitar acercarse a esta tradición que reinstaura con fuerza Jorge Velasco (...) una novela que dé cuenta del esclavismo, de los ritos africanos en el Ecuador, no podrá ser escrita ni leída sin tomar en cuenta la escritura de Velasco.

Con Polvo y ceniza, en cambio, entramos de lleno en la leyenda poptlar, en el héroe que existió. Así, Naún Briones, en cuanto mito, es en la 
novela de Eliécer Cárdenas un mito personalizado, vuelto verdad, carne, en cada uno de nosotros. Las vías para esto son tres: 1) La revalorización que se hace del marginado lojano que robaba a los ricos para darle a los pobres; 2) La sintaxis del personaje, con todas sus dudas vitales y problemas cotidianos, y 3) Por la identificación que produce en el lector a través del anhelo heroico y la coincidencia con las necesidades reales de las masas.

Además de personalizar el mito, Cárdenas lo amplía, y para ello usa a otros personajes interesantes, unos coadyuvantes, como los Quiroz, y otros oponentes-coadyuvantes, como el Aguila Quiteña, que viene a ser una especie de alter ego en contrario de Víctor Pardo, el ideólogo de izquierda que influía, no de una manera total, sino relativa, en Briones.

Por su propia naturaleza — ser la personalización de un mito $\mathrm{y}$, por lo mismo, la biografía reconstruida de un hombre erigido en leyenda-, Polvo y ceniza tiene un nivel de acciones que pueden linealizarse sin problemas. Por eso, su campo diegético es fácilmente reconocible y sólido, aunque con transposiciones de espacio y de tiempo que van demandando del lector una participación sabiamente guiada: la de armar el rompecabezas, un rompecabezas relativamente sencillo, de fácil acceso. En estos términos, Polvo y ceniza basa su estructura en la historia, en la fabulación organizada de ese mito que dispara una inmensidad de sentidos en la memoria colectiva. Con eso, Cárdenas ha logrado devolver el mito a sus orígenes y dinamizarlo erigiéndolo en símbolo, convirtiéndolo en uno más posible, en todos como lo posible.

Como una experiencia de lenguaje sumamente interesante, aunque harto compleja, debe mencionarse también Las tierras del nuaymás, de Jorge Rivadeneyra, aparecida en 1975, que es la novela de la guerrilla ecuatoriana -abortada en el caso del referente real de este texto- y la frustración de una izquierda que quiso operar, inocentemente, en las posiciones extremas. Igualmente son mencionables las novelas de Iván Egüez, desde su liviana La Linares, su ambiciosa Pájara la memoria y su muy coyuntural $E l$ poder del gran señor.

Estas novelas mencionadas hasta aquí son, a mi juicio, los mejores logros de nuestra prosa de ficción protestataria.

Considero importante consignar a continuación las consideraciones que hace Diego Araújo Sánchez (La literatura ecuatoriana de los últimos treinta años, pp. 86, 87 y 88) sobre lo que él llama el «nuevo realismo» ecuatoriano, tipificación que, en gran medida, podemos referirla también a la literatura comprometida o de protesta. Estas, aunque en forma fraccionada, por cuestiones de espacio, son: 
- En muchas narraciones del realismo social se evidencia un cierto determinismo positivista. Piénsese, por ejemplo, en los cuentos de Los que se van; en todos ellos el hombre es destruido por una violencia ciega, una especie de fatum se cierne por la naturaleza, las creencias y costumbres del ambiente, las relaciones entre los cholos y montubios, su lucha por la supervivencia.

- De una estética que pretende «reproducir la realidad y nada más que la realidad» los narradores tienden a una estética desintegradora de la realidad. Por eso, entre los caminos preferidos por algunos novelistas se encuentran la parodia, la caricatura, el esperpento. Esta es, me parece, la novedad fundamental de Alfredo Pareja Diezcanseco en Las pequeñas estaturas o en La Manticora, al igual que de Demetrio Aguilera Malta en El secuestro del general y Réquiem para el diablo. Desde en la composición de las historias narrativas, esas novelas muestran la intención paródica, el afán de aprehender la realidad a través de los espejos deformantes de la sátira.

- Del documento registrado objetiva y directamente, la captación. de realidades político-sociales, la nueva novela tiende a registrar los efectos de aquellas realidades en la conciencia o desde la conciencia de los personajes. Así en Entre Marx y una mujer desnuda, uno de los logros mayores de la nueva novela ecuatoriana (...) En las novelas de Miguel Donoso Pareja, Henry Black, Día tras día y Nunca más el mar, la realidad social se muestra en los efectos que produce en la conciencia de los protagonistas: el exilio político se manifiesta en el desarraigo de Henry Black; la represión gubernamental, la violencia, el recuerdo de la muerte del guerrillero, se expresan en el mundo cerrado y tenso del protagonista (...) El discurso narrativo de La Linares capta la realidad desde un yo intermediario que se dirige al personaje, pero también desde la subjetividad de la protagonista.

- La novela de los últimos años no renuncia al testimonio. Lo da en una forma diversa a la de los años treinta. Pero conserva ese poder.

Un trasfondo histórico como sustento de la novela aparece ya en la serie Los nuevos años, por Alfonso Pareja, novela río, como se ha dicho, que describe el desarrollo de la historia patria a partir de la transformación juliana (...) La historia social es vigorosamente testimoniada por la novela (...) El mundo cerrado e irrespirable de la burguesía provinciana tiene un puesto en la narrativa de Jorge Dávila. Los sectores populares de la ciudad provinciana tienen un puesto sobresaliente en Los hijos, la notable novela de Alfonso Cuesta (...) El lumpen proletario de Guayaquil, en la reciente El rincón de los justos de Jorge Velasco y en parte de Nunca más el mar de Donoso Pareja 4 .

${ }^{4}$ Las obras incluidas en algunos párrafos cortados a la exposición de Diego Araújo no contienen, propiamente, elementos de protesta, o carecen de calidad, razón por la cual el autor de este artículo eliminó los párrafos referidos a ellos 
- En general la novela de los últimos años prefiere la ciudad al campo. Ambiente, problemas, personajes, lenguaje están marcados por la urbe (...) El ambiente de Quito, su espacio como elemento de la sintaxis del relato, aparecen ya en obras como El chulla Romero y Flores y Segunda vida, pero asumen perfiles más hondos en obras como La Linares, Bruna, seroche y los tíos y en parte de Nunca más el mar; en esta novela los contornos de Guayaquil, la ciudad que se crea y es creada, se presentan con trazos más firmes y vigorosos ${ }^{5}$.

En lo que respecta al cuento, es mucho más difícil la puntualización de su compromiso en términos de libros, puesto que, como señala acertadamente Cecilia Ansaldo (La literatura ecuatoriana en los últimos 30 años, p. 43), «el cuento no crea un mundo objetivo completo como la novela, sino que ofrece un núcleo terminado de vida, de tal manera que su constituyente interno principal es la aglutinación y el externo la sugerencia», y «el cuento es arte para la sugerencia, de tal manera que su lectura implique un trabajo del lector a partir de los elementos evocadores de la realidad, con el mínimo detalle posible. Así, todo cuento es un camino, en cuya mitad nos vemos colocados de pronto». Esta condición sintética del cuento, esta necesidad suya de, por su propia naturaleza, sugerir, este cruzarse de caminos, en cada una de cuyas mitades nos encontramos de pronto, que es un volumen de cuentos, y ese no ser «un mundo objetivo completo», son razones suficientes para que la protesta o el compromiso puedan aparecer en tal o cual cuento y en otros no.

Otra dificultad nos la plantea su mayor antigüedad con respecto a la novela, que viene desde la más remota literatura oral, mitos, leyendas, etc.

De cualquier manera, y a grandes rasgos, hay hitos incuestionables en la narrativa corta del país, el primero el padre Juan de Velasco, en cuya Historia del Reino de Quito hay verdaderos relatos autónomos que, con desmesura e hiperbolia, recalcan la existencia y el valor de nuestra América. No es que neguemos su Historia, como se pretendió alguna vez, sino que tomamos uno de los múltiples elementos que la nutren y que movió, seguramente, a la Biblioteca de Literatura Ecuatoriana a conformar un tomo bajo el título de Zoología fantástica.

Estos textos, insertos dentro de la oposición del padre Juan de Velasco a lo que él llamó «la calumnia contra América» ${ }^{6}$, son nítidamente literatura de protesta, y de la mejor calidad.

${ }^{5}$. La literatura urbana en el Ecuador es muy anterior a El chulla Romero y Flores. Piénsese solamente que Débora, por ejemplo, publicada en 1927 , es una novela urbana.

' Arturo A. Roig subraya en Humanismo en la segunda mitad del siglo XVIII (primera parte, p. 86): «Al año siguiente de haber llegado los jesuitas expulsados a 
Dentro del costumbrismo, las viñetas de José Antonio Campos (Jack the Ripper) son literatura comprometida, en especial por la forma de asumir el habla popular en su escritura, y un antecedente muy cercano de los narradores de la década de los años treinta. En éstos, el compromiso es evidente, en el mejor sentido de la palabra, tanto en los cuentos de Los. que se van como en la mayoría de los de Enrique Gil Gilbert, José de la Cuadra, Joaquín Gallegos Lara y Demetrio Aguilera Malta. A éstos habría que agregar a Pedro Jorge Vera y a dos narradores de transición, César Dávila Andrade y Rafael Díaz Icaza, muchos de cuyos cuentos están signados por la protesta.

En los últimos tiempos, y sin alcanzar una calidad muy significativa, los cuentistas protestatarios han seguido aflorando en el país: Eugenia Viteri, Walter Bellolio, Juan Andrade Heymann (dentro de su filiación. política «china» de determinado momento) y Raúl Pérez Torres. Con mejores logros podría mencionarse a Iván Egüez y Velasco Mackenzie; también a Abdón Ubidia, aunque el sentido de su «compromiso» sea pocas veces ( $\mathrm{y}$ en sus textos menos valiosos) clasificable en los parámetros de este artículo.

En lo que se refiere a la poesía, aunque sea obvio subrayarlo, es Jacinto Collahuaso nuestro primer poeta de protesta con su Elegía a la muerte de Atahualpa, que aunque escrita en castellano y con formas estróficas españolas, dentro de los usos represivos de la época, que prohibía la utilización del quechua ${ }^{7}$, rescata una de las personalidades más significativas de nuestros orígenes.

Igualmente en la obviedad, casi como una verdad de perogrullo, Olmedo es nuestro gran poeta comprometido de la Independencia.

Otro hito importantísimo en la poesía ecuatoriana es la romántica Dolores Veintimilla de Galindo, cuya postura de avanzada dentro del romanticismo le valió que Juan León Mera, del ala conservadora, la combatiera

Europa en 1768, apareció el primer volumen de las Recherches philosophiques sur les américaines del abate prusiano Cornelio de Paurw, obra en la que se lanzaron. las más gruesas calumnias acerca de la naturaleza de América y del hombre americano.»

${ }^{7}$ El mismo Roig (op. cit., p. 66) cita a Juan León Mera, quien dice sobre esto: «El poder exterminador de la conquista arrancó de raíz el genio poético de los indios, y en su lugar hizo surgir de los abismos el espectro de la desolación y del espanto. ... Si en sentir de los dominadores españoles la inteligencia de sus víctimas no debía ocuparse ni en relatar en prosa los acontecimientos pasados, menos podrían haber consentido en que se aproximaran al Parnaso; alta y noble empresa sólo. buena para los amos, aunque fuesen unos topos, no para los esclavos, por despabilado que tuviesen el entendimiento.» 
tenazmente. Asimismo, su postura respecto a la situación de la mujer le valió el rechazo de las mentalidades más retardatarias de su tiempo. Fray Vicente Solano, por ejemplo, la atacó con ferocidad, sobre todo por la defensa que hizo ella del indígena Tiburcio Lucero, y hay quienes sostienen, entre ellos G. Humberto Mata, que fue él quien la condujo al suicidio.

Después de nuestro retrasado modernismo, el compromiso con la tierra, el hombre y la geografía de sus países está en los textos de dos de nuestros más grandes poetas de vanguardia: Jorge Carrera Andrade y Gonzalo Escudero; también en Hugo Mayo, el más radical de nuestros vanguardistas, aunque el compromiso se da en él no dentro de la vanguardia, que es donde encontramos su mejor poesía, sino dentro del naturismo de Fernán Silva Valdés y como una regresión.

Por su calidad y una producción mayoritaria en ese sentido, nuestro poeta de protesta más importante es Jorge Enrique Adoum, desde Ecuador amargo y Los cuadernos de la tierra hasta Yo me fui con tu nombre por la tierra e Informe personal sobre la situación. En él se concilian, sin duda, el compromiso social y la calidad expresiva, que es muy alta.

Uno de los mejores poemas ecuatorianos de protesta se debe a un extraordinario poeta cuya obra, en general, no es protestataria, sino más bien metafísico-mística: César Dávila Andrade. Me refiero a «Boletín y elegía de las mitas», publicado en 1956. Lo mismo podríamos señalar sobre «Poema para el hijo del hombre», que data de 1954, de Jacinto Cordero Espinosa. Igual que en el caso de estos poetas mencionados, David Ledesma Vázquez escribió un hermoso poema sobre Fidel Castro y la gesta de Sierra Maestra. Muchos excelentes poemas comprometidos se deben a Pedro Jorge Vera.

También Cazón Vera - y con gran calidad - tiene poemas de protesta, algunos incluso dentro de una tesitura místico-religiosa muy interesante.

En la mejor tradición, con una poesía sólida y excelentemente construida, habrá que mencionar textos de Rafael Díaz Icaza, Euler Granda, Antonio Preciado, Hugo Salazar Tamariz, Iván Egiiez, Fernando Nieto Cadena — sobre todo por su manejo del habla popular-, Julio Pazos, Javier Ponce, Iván Carvajal, Agustín Vulgarín - uno de los más tempranos renovadores de nuestra poesía, a quien algún día habrá que hacer justicia en este sentido- y Fernando Balseca. Hay otros, de relativa menor calidad y, en especial, más ortodoxos y panfletarios en su compromiso, como Fernando Artieda, Ulises Estrella, Horacio Idrovo, Eugenio Moreno Heredia, Luis Félix Silva, César Ayala Paredes —el «poeta soldado»- y Simón Zavala. 
Entre los más jóvenes cabe destacar a dos, de extraordinarias calidades expresivas y temáticamente comprometidos: Francisco Torres Dávila y Diego Velasco.

\section{OBRAS CITADAS}

Adoum, Jorge Enrique: La gran literatura ecuatoriana del 30 (Quito: El Conejo, 1984).

_-: Entre Marx y una mujer desnuda (México D. F.: Siglo XXI, 1976).

-: Ecuador amargo (Quito: CCE, 1949).

_-_: Los cuadernos de la tierra (Quito: CCE, 1952).

- - Yo me fui con tu nombre por la tierra.

- Informe personal sobre la situación (1973).

Aguilera Malta, Demetrio: El secuestro del general (México D.F.: Joaquín Mortiz, 1973).

- Réquiem para el diablo (México D. F.: Joaquín Mortiz, 1981).

Agullera Malta, Demetrio; Gallegos lara, Joaquín, y Gil Gilbert, Enrique: Los que se van (Guayaquil: Zea \& Paladines, 1930).

ANDrade, Roberto: Pacho Villamar (Guayaquil: Imprenta de la Concordia, 1900).

Andrade Heymann, Juan: El lagarto en la mano (Quito: El Conejo, 1984).

ANSAldo, Cecilia: La literatura ecuatoriana en los úlitimos 30 años: «El cuento ecuatoriano en los últimos 30 años» (Quito: El Conejo, 1983).

Araújo SÁnchez, Diego: La literatura ecuatoriana en los últimos 30 años: «Tendencias en la novela de los treinta últimos años» (Quito: El Conejo, 1983).

BALSECA, Fernando: «Informe especial: poesía actual en el Ecuador», en Revista Diners, núm. 56 (Quito, 1987).

- : «Tambores de novela fuerte para la mala lectura de canciones perdidas», en Crónica del río, núm. 1 (Guayaquil, 1986).

CÁrdenas, Eliécer: Polvo y ceniza (Quito: El Conejo, 1983).

Cordero Espinosa, Jacinto: «Poema para el hijo del hombre», en Lírica ecuatoriana contemporánea, tomo I (Bogotá: Círculo de Lectores, 1979).

Cuadra, José de la: Los Sangurimas (Quito: El Conejo, 1984).

Cuesta y Cuesta, Alfonso: Los hijos (Mérida: Talleres Gráficos de la Universidad de los Andes, 1962).

Cueva, Agustín: Lecturas y rupturas (Quito: Planeta del Ecuador, 1986).

DÁvIlla ANDRADE, César: «Boletín y elegía de las mitas», en Lírica ecuatoriana contemporánea, tomo I (Bogotá: Círculo de Lectores, 1979).

Donoso Pareja, Miguel: Henry Black (México D.F.: Diógenes, 1969).

- Días tras dia (México D. F.: Joaquín Mortiz, 1976).

—_: Nunca más el mar (México D. F.: Premiá, 1981).

Egüez, Iván: La Linares (Quito: Centro de Publicaciones de la PUCE, 1976).

- : Pájara la memoria (Quito: Planeta, 1984).

- : El poder del gran señor (Quito: El Conejo, 1984).

FARías, Aníbal: «El lugar de la poesía», ponencia en el III Encuentro sobre Literatura Ecuatoriana (Cuenca, 1984). Inédita.

Gallegos LaRA, Joaquín: Obras escogidas (Guayaquil: CCE, 1981).

Gil Gilbert, Enrique: Nuestro pan (La Habana: Casa de las Américas, 1983).

ICAZA, Jorge: Huasipungo (Quito: Imprenta Nacional, 1934). 
- El chulla Romero y Flores (Quito: CCE, 1958).

- En las calles (Quito: El Conejo, 1985).

Lunacharsky, Anatoly V.: El arte y la revolución (México D. F.: Grijalbo, 1975).

Martínez, Luis A.: A la costa (Quito: Imprenta Nacional, 1904).

Montalvo, Juan: Capítulos que se le olvidaron a Cervantes (Besançon: Imprenta de P. Jacquin, 1895).

Montesinos Malo, Arturo: Segunda vida (Cuenca: CCE, 1962).

Palacio, Pablo: «Vida del ahorcado», en Un hombre muerto a puntapiés (La Habana: Casa de las Américas, 1982).

Pareja Diezcanseco, Alfredo: Los nuevos años: la advertencia (Buenos Aires: Lo. sada, 1956).

—- Los nuevos años: el aire y los recuerdos (Buenos Aires: Losada, 1959).

- L Los nuevos años: los poderes omnimodos (Buenos Aires: Losada, 1964).

- Las pequeñas estaturas (Madrid: Revista de Occidente, 1970).

- : La Manticora (Buenos Aires: Losada, 1974).

—.: El muelle (Quito: El Conejo, 1985).

Riofrío, Miguel: La emancipada (Quito: El Conejo, 1984).

Riyadeneyra, Jorge: Las tierras del Nuaymás (Barcelona: Planeta, 1975).

RojAs, Angel F.: Exodo de Yangana (Buenos Aires: Losada, 1949).

SAlvador, Humberto: Trabajadores (Quito: El Conejo, 1985).

Tovar, Carlos R.: Timoleón Coloma (Quito: El Conejo, 1984).

Velasco, Juan de: Zoología fantástica (Bogotá: Oveja Negra/El Conejo, 1986).

Velasco Mackenzie, Jorge: El rincón de los justos (Quito: El Conejo, 1983).

- - Tambores para una canción perdida (Quito: El Conejo, 1986).

Vera, Pedro Jorge: Los animales puros (La Habana: Casa de las Américas, 1985).

YÁnEZ, Alicia: Bruna, soroche y los tíos (Quito: CCE, 1973). 
